\title{
THE INFLUENCE OF POLLINATION ON THE DEVELOPMENT OF THE HOP.
}

\author{
Br ALBERT HOWARD, M.A., F.L.S., \\ Botanist to the South-Eastern Agricultural College, Wye; \\ Formerly Scholar of St John's College, Cambridge.
}

IN general the hop is dicecious. Sometimes, however, in gardens of the Bramling variety, hills are met with from which bines arise bearing both male and female flowers. Such monœcious plants are rare.

The male flowers: The inflorescences bearing the male flowers are much-branched cymose panicles, arising eitber from the axils of the main stem or from the axils of the lateral shoots.

Each flower is about a quarter of an inch in diameter, and consists of a five-leaved sepaloid perianth, opposite which are five stamens with short filaments and long anthers, which liberate their pollen by longitudinal dehiscence $(1,2,3$, Fig. 1)

The female flowers: The female flowers occur in definite inflorescences (strobiloid spikes) which are borne on branches arising directly from the leaf axils of the main stem itself, or from the axils of the leaves upon lateral shoots produced by the main stem. These inflorescences give rise to the hops of commerce. Each female flower is very minute and consists of a cup-shaped perianth, partially surrounding the superior ovary, which contains a single ovule and which is surmounted by two long stigmas covered with elongated papillæ $(4,5$, Fig. 1). At this stage (as a rule early in July) the hops are said to be "in burr." After the stigmas or "brush" of the young hops drop off there is a rapid growth of the bracts of the strobile, giving rise to the fir-cone shape of the mature inflorescence (7, Fig. 1). The bines are now said to be "in hop."

Journ, of Agric. Sc̣i, I 
50 Influence of Pollination on Development of the Hop

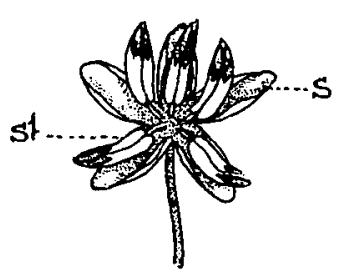

I.

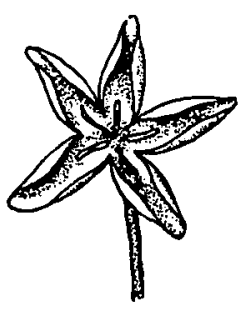

2.

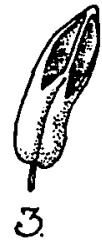

3.

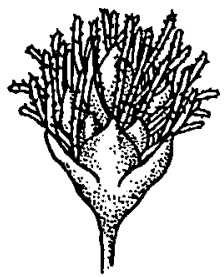

4.

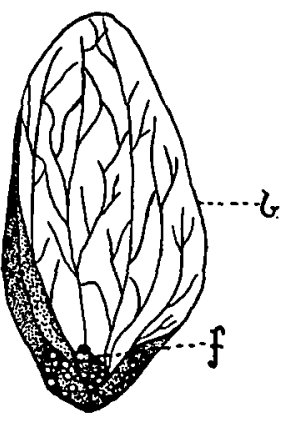

6.

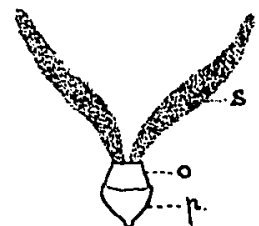

5 .

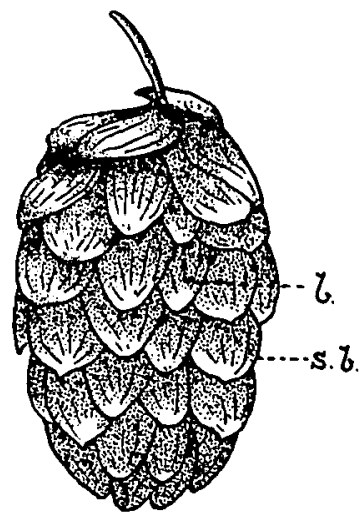

7.

Fig. 1.

1.-A male hop flower. $s$ perianth (sepal); st stamen.

2.-Perianth of male flower with anthers removed; the fine short filaments are visible. 3.-A stamen showing the dehiscence of the anther.

4.-A young female inflorescence (a hop "in burr") showing the stigmas (" brusb"). 5.-A complete female flower. $p$ the cup-shaped perianth; 0 ovary; $s$ stigma.

6.-A bracteole (b) surrounding the ripe fruit (" seed ") $f$.

7.-A ripe hop showing the stipular bracts (s $b)$ and bracteoles (b).

$$
\text { (1-6 } \times 3,7 \text { natural size.) }
$$


During the "growing out" period, which usually lasts about six weeks, it will be observed that there are two very distinct kinds of bracts in the strobile. At the four corners of the hop occur the seedless stipular bracts (7, Fig. 1), which are further distinguisbed by their greenish colour, the limited development of lupulin glands and their acuminate apex. On the flat sides, the rounded, bright yellow, seedbearing bracteoles ${ }^{1}(6,7$, Fig. 1) occur in pairs.

While carrying out various cross-fertilisation experiments during the past summer, it was noticed that the young hops which were not pollinated, and which served as check experiments or controls, always remained in burr for a much longer period (often more than a week) than those which were pollinated. On the other hand, it was found that when the young hops were artificially pollinated, the stigmas turned brown and withered in three or four days and then fell off. The dying away of the stigmas was at once followed by the growth in size of the young bops. In a word, the pollinated hops started to grow out at once, while those which had not received pollen did not develop immediately, but waited, as it were, for this process to take place. Thus as the pollinated hops began growth a week to ten days before the controls, it became a matter of great interest to follow the subsequent development of both.

It was found that the non-pollinated hops never recovered their lost ground. They turned out at picking time to be small, green and unripe, and compared very unfavourably with the well-grown, golden yellow and ripe pollinated hops. The difference between the two sets was so great in all respects that they would never have been taken for hops of one variety, much less for hops growing on the same bine and on opposite pairs of laterals. While the controls were very small and green, the pollinated hops only differed from the normal hops on the same bine in being rather more symmetrical and better developed specimens with the free ends well closed in.

The differences between the two sets of hops at picking time may be seen in Fig. 2, Plate II. The control hops are in the centre, the bunches on either side having been pollinated. Fig. 2 represents three bunches of Colegate's hops from the same bine, and developed from laterals of nearly equal strength. The control bunch in the centre is quite seedless, while the pollinated bunches on either side are wellseeded.

1 The stipular bracts and bracteoles of the hop are spoken of as "petals" by the hop-growers. 


\section{Influence of Pollination on Development of the Hop}

A further point of some interest was noted when the experimental hops were picked. It was found that the controls; which in all cases turmed out to be seedless, were attacked by mould (Spharotheca humuli, [DC] Burr.) to a much greater extent than the seed-hops which had been pollinated. Indeed these latter were singularly free from this parasite. Fertilisation therefore seemed not only to stimulate the growth, to hasten ripening, and to improve the colour, but also to increase the mould-resisting power of the hop itself.

The behaviour of the experimental hops suggested the desirability of extended observations in hop gardens to determine, if possible, whether the above results, arrived at under somewhat artificial conditions, are borne out in actual practice.

In the first place, a very large number of nearly ripe hops were examined in order to determine to what extent seed-production takes place. No well grown-out hops were seen without seeds. Further, it was found possible to count the seeds in any hop by observing the size of the bracteoles. Where seeds have set, the bracteoles are much larger and brighter yellow than those which only bear rudimentary seeds. In Fig. 3, bracteoles with (A), and without (B) fully developed seeds are showr. In all cases those with mature seeds are larger than those with rudimentary seeds. The hops on the right and left (C) represent extremes of well grown-out seed hops. The two hops (E) are seedless hops from a control bunch, while (D) represents a hop from a pollinated bunch. The difference in size of the bracteoles with and without perfect seeds is well seen in the large hop on the left (C).

Since the stigmas at the stalk-end of the hop are ready for pollen first, after which those towards the free end become successively receptive, a considerable period elapses between the beginning and end of pollination in any particular hop. In view of the scarcity of males in many gardens at the present time it appeared probable therefore that hops would be found seedless at the base, fertile at the free end and vice versá. A search showed that this was the case. In a garden which contained only three male hills in fourteen acres numerous hops were found seedless and small at the base, but fertile and enlarged at the free end. Others were found seedless and constricted in the centre only. Fig. 4 illustrates this point.

It was next noticed that fully developed seed hops and badly grownout, unripe, seedless hops were often to be found on the same bine. In such cases, pollen was probably abundant when the earliest hops on 
the bine were in burr, but was not available when the later hops were ready for pollination. Hence, in order to obtain all the hops on a bine in a well grown-out condition pollen must be available during the whole burr period.

Evidence on the subject of the special liability of seedless hops to mould attacks was now sought in the field. It will be remembered that in the cross-fertilisation experiments it was noticed that the seedless hops in the control bunches were attacked by mould to a much greater extent than the seed hops on the same bine. Accordingly, a large number of half seedless hops were examined to see whether the mould did more damage on the seedless part than on the seeded portion. This was found to be the case. The seedless portions were usually completely destroyed, while the fertile portions grew out almost normally (Fig. 5). Further, in hops which contained only one or two fertile bracteoles it was constantly seen that these structures were hardly affected, while the rest of the hop was destroyed (3-5, Fig. 5).

The above experiments and observations all point to the necessity of fertilisation in the production of well-grown bops of the desired colour. On the other hand, the absence of fertilisation leads to small, green, unripe hops, particularly liable to damage by mould. As is well known, it is during the burr stage that hops are liable to total destruction by mould. This seems, apart from climatic considerations, due to two main causes. In the first place, the feathery stigmas arrest the mould spores as they blow past, and also tend to keep the atmosphere around the spores moist and so assist in their germination. Secondly, unless pollination takes place as soon as the stigmas are receptive there seems to be a pause in development, during which the hop waits for the process to take place. It would appear, therefore, that any arrest of growth at this period is particularly dangerous, and everything should be done to carry the young hops rapidly through this critical phase.

It seems difficult, therefore, to escape the conclusion that, under the conditions obtaining in Kent, the growth of seed hops rather than seedless hops should be aimed at. Before, however, any special recommendations are made on such an important subject as this, it is proposed to carry out further investigations during the coming season on the lines indicated below. The present experiments are put forward merely as a contribution to the subject. 


\section{Influence of Pollination on Development of the Hop}

The advantages of growing seed hops seem to be the following:

1. Large, heavy, brightly coloured, and well grown-out specimens.

2. Early ripening.

3. Increased mould-resisting power.

The disadvantages, on the other hand, would appear to be:

1. The space taken up and the trouble involved in growing suitable males for the various gardens. It is obvious that unless the males shed their pollen when the hops are in burr they are useless as far as the particular garden in which they are growing is concerned. There seems to be quite as much variation in the time of ripening among male hops as there is among the females. Further, it appears that a good many of the males met with in hop gardens ripen too early and shed most of their pollen before the surrounding hops are in burr. Some trouble, therefore, would have to be taken to select and grow male hops which would correspond to the full burr period of the various varieties grown in the south-eastern districts of England. Probably suitable males could be raised from seeds.

2. The possible difference in brewing value between seed and seedless hops. The Germans say that 116 lbs. of seed hops are equal, in this respect, to $100 \mathrm{lbs}$. of seedless hops. Next season it is proposed to estimate the total resins present in equal weights of seedless and seed hops in several of the more important English varieties. With regard to this point, however, it might be mentioned that, in all the cases examined this year, it was found that the lupulin glands of the seedless hops were not so ripe at picking time as those in the seed hops on the same bine. This difference in ripeness therefore may lead to some difficulty in carrying out the proposed experiments.

3. The possibility of the more rapid exhaustion of the hills through the more frequent formation of perfect seeds. In order to throw light on this point an analysis of hop seeds (Early Bird Bramlings) has been made by Mr F. T. Holbrook. The results are given in the following table, together with the figures relating to the whole hop.

It will be seen that the seeds are richer in nitrogen and phosphoric acid. In view, however, of the liberal manner in which hops are manured, it is hardly likely that increased seed production will either exhaust the soil or weaken the plant.

The opinions of several leading Kentish hop-growers were now sought on this question of the value of male plants. The views ob- 
Analyses showing the fertilising constituents contained in hops and seeds, stated in parts per 100 of the materials as taken from the pocket.

\begin{tabular}{|c|c|c|c|c|c|}
\hline & Ash & Nitrogen & $\begin{array}{l}\text { Potash } \\
\left(\mathrm{K}_{2} \mathrm{O}\right)\end{array}$ & $\begin{array}{c}\text { Phosphoric } \\
\text { Acid } \\
\left(\mathrm{P}_{2} \mathrm{O}_{5}\right)\end{array}$ & $\begin{array}{l}\text { Lime } \\
(\mathrm{CsO})\end{array}$ \\
\hline Whole hops............... & $6 \cdot 33$ & 3.22 & $2 \cdot 45$ & $1 \cdot 18$ & 1.06 \\
\hline Seeds................................... & 6.53 & $4 \cdot 64$ & $1 \cdot 39$ & $2 \cdot 33$ & $\cdot 46$ \\
\hline
\end{tabular}

tained differed widely. Many regard the males as useless and bave them grubbed after picking time. Others, especially in East and Mid Kent, consider that a few males are useful and inprove the general welfare of the gardens. $\mathrm{Mr} \mathrm{W} . \mathrm{H}$. Hammond, of Canterbury, in a very interesting letter dated October 17th, 1904, sums up his experiences as follows:

"With regard to male hops in our gardens in East Kent, I have all my life understood from growers that they thought it an advantage to have a few male plants scattered about. My father, who was a large planter in the Petham Valley for sixty years or more, always grew a few males.

"The perfect seeds for one thing help to make weight, and our English brewers do not object to them, but upart from that many men seem, in the past, to have had an idea that it was better for the general welfare of the gardens if there were a few males present.

"I can recollect talking this matter over more than thirty years ago with the late Mr S. J. Sankey, of South Hill, Hastingleigh, when be instanced the case of a garden at Hastingleigh Court Lodge Farm, which had always been a good one and had always had a considerable number of male plants in it, but at one time a fresh tenant came who thought them useless, and destroyed them all; after that the garden moulded, went to the bad, and was soon grubbed.

"Personally, I have always thought it best to keep a few male plants in my own garden."

Mr H. O. Hubble, of Hunton, Maidstone, writes:

"I consider that the influence of the male hop in a hop plantation is decidedly a matter worthy of further experiments on your part, especially because the results you have already obtained seem conclusively to prove 


\section{Influence of Pollination on Development of the Hop}

what some growers in Mid Kent have for many years believed, as the result of observation only.

"I cannot pose as an 'experienced grower,' but I have often noticed that the female hops in close proximity to a 'seeder' ' come into hop earlier, are larger and more mature, in fact are generally more 'complete,' if I may so put it, than those which are not so situated.

"The rule does not, of course, always hold good, but that, you have explained, is because the male hop has come to maturity either too early or too late for 'pollination' to take place.

"Your'statement that a 'pollinated' hop is better able to resist mould is extremely interesting and valuable, and the fact that 'pollinated' hops always contain seeds is surely a weighty argument in favour of the preservation of the male plant.

"My uncle, a grower of long experience, has always insisted on the value of the male plants, and would always have some of them planted about each garden, and there are other large growers in this district who think and act in the same way."-(Letter, Nov. 4th, 1904.)

Turning now to the literature of the subject the greatest diversity of opinion is found. The German investigators seen to agree on this question, and regard male hops as useless or even harmful. It is even said that male plants are not allowed in Spält under a heavy penalty. The hops from this district, however, are not seedless, but contain seeds, so that the efforts made in striving after a seedless hop are not altogether successful.

The American growers, on the contrary, think that imperfect fertilisation is a frequent cause of light weight hops of inferior quality. A leading Oregon grower relates his experience as follows:

"This complaint of the Germans of seeds in American hops was first heard in 1882, when hops were so high, and caused some growers on this coast to grub out and destroy all their male vines. The result was that their hops did not mature well. They were large, green, light, feathery things, with neither colour nor strength, and dealers would not handle them. I have seen this experiment tried in Soutbern Oregon with the same result. I planted a yard myself once without being able to get male roots, and my hops were poor, lean things, until I obtained the male plants and got them to grow vigorously, when my hops became of good colour when ripe, with plenty of strength, and I heard no more complaints of poorly matured or lean hops. I am now fully

1 In Kent, male hops are sometimes called " seeders." 
convinced that hops, like many other plants, require fertilising from the bloom, and, as none but the male hop bears any pollen, it is necessary to have a sufficient number of these in a hop yard, so that the flowers of each vine may be fertilised. And brewers, if they expect a good, solid, bright-coloured, well-matured hop, well filled with lupulin, must expect also to see the hop well filled with good, large, purple seed. If they do not wish seed they cannot expect lupulin. Germany may produce good hops without seed, but it cannot be done here, at least such has been my observation and experience. Therefore my advice is to let the male hop alone, and if in a season of high prices a few brewers complain of extra weight in the seed, pay no attention, but go ahead!."

It nust be remembered, however, that the conclusions of observers in Germany and the United States, although of great interest, are not necessarily applicable to the conditions which obtain in England. The varieties cultivated abroad are not the same as those grown in this country, the climatic conditions are widely different, and there does not seem to be the same danger from mould as in England.

The directions in which further work is desirable in this subject seem to be as follows:

1. The effect of pollination and its absence in gardens which are particularly liable to mould at the present time. It is well known that, other things being equal, mould is most prevalent where the air is still, and where the hops are "housed in." In such situations there is also the smallest chance of pollination, and it is possible that the lack of pollen may partly account for the damage done by mould.

2. The effect of pollination in gardens where the hops do not usually grow out well.

3. The influence of temperature and moisture on the liberation of pollen and the spread of mould. Generally speaking, damp, cold weather favours mould and also checks the liberation of pollen.

4. The possible relation between the percentage of seed and the total crop. Fertilisation seems to stimulate the growing out of the hop, and its absence has the reverse effect.

5. The comparison of the brewing value of seedless and seed hops. The determination of the total resins seems to be the best way of arriving at an opinion on this point.

6. Comparative infection experiments with mould on seed and seedless hops.

1 The Hop-its culture and cure, В. Myrick. 


\section{Influence of Pollination on Development of the Hop}

7. The influence of pollen from different males on the development of particular varieties.

8. The effect of various washes on hops when in burr. Possibly fertilisation may be interfered with or even prevented when hops are sprayed at this stage.

9. The influence of seed formation on the "thickness" of the sample as taken from the pocket.

10. The effect of fertilisation on the compactness or "density" of the hop.

As far as possible these lines of enquiry will be followed up during the coming year. 